\title{
Sheffield

\section{Emotion management and occupational therapy student learning on placement: A post-structuralist exploration}

HEALEY, Joan

Available from Sheffield Hallam University Research Archive (SHURA) at:

http://shura.shu.ac.uk/17268/

This document is the author deposited version. You are advised to consult the publisher's version if you wish to cite from it.

\section{Published version}

HEALEY, Joan (2017). Emotion management and occupational therapy student learning on placement: A post-structuralist exploration. British Journal of Occupational Therapy, 80 (11), 676-683.

Copyright and re-use policy

See http://shura.shu.ac.uk/information.html 


\section{Abstract}

Emotion management and occupational therapy student learning on placement: a post-structuralist exploration.

Introduction:

The role of emotion management and emotional labour has been extensively debated and theorised in nursing and medical literature but until recently there has been very little written from an occupational therapy perspective

\section{Method:}

This doctoral research explored the emotional aspects of placement learning with a group of third year occupational therapy students using a post-structural theoretical framework and methodology. A creative arts based qualitative methodology was employed. The researcher facilitated creative writing groups in which students produced stories and poems about placement experiences. The writing, the group discussions and the one to one conversations were analysed with post-structuralist and narrative theory.

\section{Findings:}

The innovative method produced writing that evokes the placement experiences and captures the students' endeavours to manage their emotions in order to 'perform the professional'. The findings reveal the role of emotion management in the discourses of professionalism in the health and social care environment.

\section{Conclusion:}

The research raises questions for the occupational therapy profession about the hidden emotional aspects of our practice and proposes an alternative view of emotion management to that which is implied in the concept of emotional intelligence. 
Emotion management and occupational therapy student learning on placement, a post-structuralist exploration.

\section{Introduction and theoretical issues:}

The role of emotional labour and emotion management in health care professional practice is discussed in literature across the health and social care professions, particularly medicine, nursing and social work. Occupational therapists work within the same professional milieus and deal with similar potentially emotionally challenging situations on a daily basis. Although there have been some seminal publications about the role of spirituality, empathy and caring in the profession for example, Peloquin (1989) and Egan (2007) which allude to the emotional dimensions of our practice, there has not been any specific exploration of emotional labour or emotion management within the occupational therapy profession. The exceptions to this are Clouder's 2006 article exploring caring as a threshold concept in occupational therapy student learning and the recent published articles which explore emotional intelligence and occupational therapy (Chaffey, Unsworth and Fossey, 2012; McKenna and Melson, 2013; Andonian, 2013).

It is important to define the differences between the concepts of emotional labour, emotion management and emotional intelligence, although they are often used interchangeably in the literature. Emotional labour is a concept derived from the work of the sociologist Arlie Hochschild in 1983 from her landmark study of air flight attendants in the USA and how they were required to present themselves and manage their emotions as part of their role. It was published as The Managed Heart. Commercialisation of Human Feeling (1983, 2003). Hochschild defined emotional labour as being the required management of emotional expression and feeling in order to carry out a job. She described how the stewards engaged in surface acting when they had to appear happy in order to keep the passengers happy. Deep acting was required when the individual had to work on their inner feelings to change the way they felt to the 'appropriate'/required aspect for the role. This deep acting involved working upon the self to change the self to match the 'feeling rules' of the company or organisation.

Emotion management is a more general concept that uncouples the activity from any exchange value of a specific paid job role and tends to view it as an individual activity 
performed according to environmental, cultural and personal demands. It involves the person modifying their expressed emotion in specific situations.

Emotional intelligence focuses more on individuals' abilities to be aware of and regulate their emotions according to the demands of a situation. Whereas emotional labour and emotion management stress the social constructionist aspect of emotion management, emotional intelligence, coming from the discipline of psychology and a more positivist approach, is more individually orientated and looks at how individuals acquire the emotion management skills required of them

These differences in approaches to emotion management come from a significant epistemological division between those who see emotions as being intrapersonal and those who see them as interactional and relational (Campos et al, 2011). The epistemological debate divides between the positivist empiricist view of emotions being something innate, physiological and/or psychological that can be measured and observed, to a constructionist continuum where emotions are seen as culturally mediated expressions of inner states that are politically and culturally defined and determined (Gergen, 1999). These debates are being conducted across disciplines in areas such as psychology, philosophy and sociology. I would suggest it is an area of debate for occupational therapists as well as this could be seen to be linked to what has been highlighted as the paradigm challenges within the profession (Hooper and Wood, 2002 ). Aligning the profession with a positivist concept of emotions may not express the full complexity of the philosophical base underlying our unique professional practice.

\section{Literature review:}

The concept of emotional labour was first introduced in the nursing literature by James (1989) and Smith (1992) and has been a significant issue ever since then (Riley and Weiss 2016) including seminal works by Bolton (2005) and Theodossius, (2008). The need for other health and social care professions to study the concept has been raised (Mann, 2005).

Issues around the emotional demands of medical training are frequently discussed within the Medical Education journal including debates about the concepts of emotional labour and emotional intelligence McNaughton (2013), Monrouxe et al 
(2014). Similarly in Social Work literature there have been several articles, which discuss the emotional content of social work and how students and practitioners manage their emotions within this (Barlow and Hall 2007, Dwyer 2007, Ingram 2015).

The literature reflects a wide range of conceptual understanding of what constitutes an emotion and indeed from nursing, McClure and Murphy (2007 p105) talk of the 'semantic morass' of the literature around emotional labour. Occupational therapy literature also displays this confusion with terms.

Although we are a profession with a focus on the importance of the therapeutic use of self, holism and client-centred practice there has been no explicit research into the emotional aspects of our professional practice. Some occupational therapy authors have highlighted issues around the profession's lack of focus on the 'felt' experiences of those we work with. Nicholls (2007) discussed our lack of attention to the distress experienced by many of the service users we work with and posits the idea that perhaps this neglect is to do with our own fear of these emotions. Nicolls et al (2013) outlined a relational model of occupational therapy that recognises that emotions are involved in the dynamic relationship between the therapist, the patient and the occupation. These authors use a very specific concept of emotions from psychoanalytical theory which they apply in their therapeutic work. Egan's 2007 article focused on suffering, asked why, as a profession, we do not speak of the suffering that we come in to contact with every day and suggests this may be because we view it overwhelmingly as the focus of what we are trying to prevent or lessen.

Whilst the studies by Chaffey, Unsworth and Fossey (2012), Andonian (2013) and the article by McKenna and Melson (2013) are a welcome acknowledgment of the emotional context of occupational therapy practice they utilise concepts of emotional intelligence without an explicit critique of the epistemological underpinning of the concept. They do reference the emotional labour involved in practice but assume an authentic individual self, divorced from the power relationships within the field of health care practice.. These studies into emotional intelligence and occupational therapy regard emotion management as a skill to be linked with other competencies. McNaughton (2013 p74) refers to emotional intelligence as 'the dominant technology 
through which particular ideas about emotion become operationalised both in medicine and throughout our day to day lives'.

Clouder's study (2006) of occupational therapy students, mentioned earlier, takes a more social constructionist view of emotions. She addresses the experience of caring, some aspects of which are very much concerned with emotional dimensions and she recognises the health professions' unwillingness to acknowledge the affective aspects of practice in favour of the technical/rational.

Although there are a variety of approaches to emotions in the literature, almost all of them revolve around an understanding of a humanist concept of the individual assuming agentic powers and choices and an authentic coherent 'self' including individual emotions. Within the studies on emotional labour in health and social care, issues about the nature of the demands about what can and cannot or should and should not be felt and expressed in different areas of practice are acknowledged but rarely problematized. Zembylas (2007) highlighted that much of the research around emotion and education in his case, rarely make the theoretical assumptions about emotions explicit and this is similarly true of the studies on emotional labour in health care

\section{Post structuralism and emotions}

My study was based on a very specific poststructuralist theoretical approach moving away from an individual, competency based view of emotions to one where emotions are understood to be more social and discursive and embodied experiences that flow through our experience of professional practice.

Poststructuralist concepts of emotions make explicit the power discourses within different contexts and demonstrate how emotion management is part of the discourses of becoming a health professional, and by which student occupational therapists are constituted and constitute themselves as professional heath care workers.

I used the work of Foucault (1982) and his studies of the relationships between knowledge and power and what happens as a result of the ways in which power circulates through our everyday practices. In this research investigating the emotion management of students on placement, the power relations enmeshed in the institutions and scenarios within the health care service were always apparent. My 
understanding of the role of the relationship between the modern health care system and the students learning to be professionals within it was informed by Foucault's (1982) concepts of governmentality which involves both technologies of domination and 'technologies of self' (Foucault, 1988). Emotion management can be seen as just such a 'technology of the self', a self- disciplinary technique or practice where students and professionals discipline their emotions to conform to the requirements of their work environment.

Poststructuralist critiques of the great Enlightenment ideals of reason, humanism and grand meta-narratives emerged in the latter half of the twentieth century. Unlike a positivist approach where the aim is to 'capture' a reality in research, a poststructuralist aims for different representations of experience, multiple perspectives constructed at specific moments in time for a specific audience or context (Denzin, 2013). Within poststructuralist theory, truths and knowledge are held to be the result of particular interests and contexts (MacLure, 2013). For a poststructuralist researcher then, there are multiple interpretations of situations and events which are interpreted and re-presented according to social contexts and discourses. My research was an exploration and evocation rather than an attempt to discover truths. I aimed to explore what it may feel like to students to have to manage their emotions on placement and to explore what emotion management does in the wider discourse of occupational therapy within health and social care.

\section{Method:}

The post structuralist epistemology informed the approach and design of my research. In order to explore the multiple interpretations of events on placement I used an arts based narrative approach (Bochner and Ellis, 2003) incorporating creative writing for my research. Using creative writing workshops for students to write about and discuss their placement experiences opened up a field of exploration which disrupted the usual academic approach and relationships. I wanted this 'troubling' of academic and existing discursive practices to enable to the participants to access their experience through different lenses.

Recruitment: I recruited seven final year occupational therapy students from two cohorts on two pre-registration programmes at the university. All were in their final year and were soon to start their final placement. Their previous placements had 
finished at least six months previously so that they had had time to process any particular issues which may have arisen. Workshops and follow-up individual discussions were arranged at convenient times.

Design: The four creative writing workshops each lasting three hours took place over a period of eight weeks and were held at the university. Individual discussions were held shortly after the end of the groups. The workshops followed a similar format each week. Fig 1 lists the prompts used for the writing exercises in each group. Participants were asked if they wanted to read out their work to the group and discussion of the writing followed when someone shared their work. All the workshops were recorded and transcribed as were the one-to-one discussions. Students chose which pieces of their writing they wanted me to have for the research at the end of the workshops.

Fig 1 Writing workshops

\begin{tabular}{|l|l|l|l|l|}
\hline & Prompts & Prompts & Prompts & aims \\
\hline Group 1 & $\begin{array}{l}\text { 1.1. The land of } \\
\text { placement }\end{array}$ & $\begin{array}{l}\text { 1.2. OT as an } \\
\text { animal }\end{array}$ & using metaphor \\
\hline Group 2 & $\begin{array}{l}2.1 . \\
\text { Approaching } \\
\text { placement }\end{array}$ & $\begin{array}{l}\text { 2.2. Your } \\
\text { professional } \\
\text { face }\end{array}$ & $\begin{array}{l}\text { 2.3. Managing } \\
\text { your emotions }\end{array}$ & rich description \\
\hline Group 3 & $\begin{array}{l}\text { 3.1. A poem } \\
\text { about } \\
\text { placement }\end{array}$ & $\begin{array}{l}\text { 3.2. An } \\
\text { inspirational } \\
\text { person from } \\
\text { placement }\end{array}$ & $\begin{array}{l}\text { 3.3. From } \\
\text { another's } \\
\text { perspective }\end{array}$ & $\begin{array}{l}\text { fiction - writing } \\
\text { from another's } \\
\text { perspective }\end{array}$ \\
\hline Group 4 & $\begin{array}{l}\text { 4.1. Poem by } \\
\text { David } \\
\text { Constantine }\end{array}$ & $\begin{array}{l}\text { 4.2. Feeling } \\
\text { rules }\end{array}$ & $\begin{array}{l}\text { 4.3. Where do } \\
\text { the rules come } \\
\text { from? }\end{array}$ & $\begin{array}{l}\text { the feel of } \\
\text { placement }\end{array}$ \\
\hline
\end{tabular}

(Prompts were developed from a thematic analysis of two pilot study discussion based focus groups)

Narratives may be about forming meanings but they do not necessarily have to form coherent, one dimensional truths. Narratives can also enable us to look at multiple interpretations and multiple layers of meanings (Andrews, Squire and Tamboukou 2013). I chose to use group workshops rather than individual journals in order to explore the social or dialogic aspects of narratives within the student group. It allowed me to look beyond the individual stories and be able to focus on how the stories are produced and structured to explore the power relationships within 
dominant discourses of professionalism and emotion management amongst the students.

Empirical concepts of validity rely on a humanist understanding of the legitimacy of knowledge claims that relate to a truth that can be represented. In rejecting research as being about seeking truths and accepting the impossibility of re-presenting reality and experience, the idea of validity becomes both problematic and complex. Lather (1993) explored different and challenging concepts of validity and her ideas about transgressive validity have informed this research in so far as they reflect what she describes as 'paralogical validity', that is looking for differences not heterogeneity, looking for complexity and contradictions and avoiding a desire to make a coherent sense of an unknowable 'reality' and an explicitly partial and situated perspective that is interrogated with author reflexivity.

There are also other important dimensions to validity in this type of research which have variously been referred to as plausibility and resonance (Richardson, 2000) in that what is produced is felt as recognisable by people in the context. Ellis and Bochner (2000) describe how the narratives produced in research can be judged by how well they facilitate understanding, feelings and engagement in the reader or listener. I was hoping that the stories the student participants produced would provoke recognition and emotional understanding in readers or listeners.

In order to preserve the complexity of the data as opposed to simplifying it, I did not do a thematic analysis. In the mapping of the work and the groups and conversations I sought to find instead, connections, challenges and silences where data stood out or where there were intersections and counter narratives both within individual work and across the group and myself. I began the 'data analysis' process by reading and re-reading the transcripts and work and listening to anything people had read out to the group. I then began mapping the content of individuals' written pieces alongside their contributions in discussions and in their post-group conversation with me to create connections and possible meanings and an over-all dialogic narrative for each person. I then mapped each group session and identified what was shared, what was said and what was not said or shared. That gave me a sense of the discourse of student learning circulating within the room. I then looked at other writing that had 
not been read out but had been shared with me after the groups finished and investigated that for feelings that did not correspond to the dominant discourse within the room. I was not seeking thematic congruence in the material across the individual or the groups but rather looking for routes through the individual, group and public narratives.

Ethical issues: The proposal was passed by the University Research Ethics Approval Board 12/09/12 and the usual ethical processes were followed. The names of all the participants have been changed and minor details altered where there was potential for other individuals to recognise themselves in the writing. Ground rules for the group were negotiated and there was a senior member of the placement team available for support during the groups if anyone wanted to leave and talk through anything that had happened to them on placement.

The students produced some very moving pieces of work which combined with the discussions in the group and follow-up conversations really illuminated the affective dimension of their placement learning. The 'technologies of the self' (Foucault 1988) evident throughout, are another layer or twist in the assemblage of power relations and discursive practices (Tamboukou, 2003) in the health and social care settings. What their writing also illustrates is their narratives of subjectivities, how they create themselves as professional occupational therapists and are created by the social practices in which they engage in these contexts.

\section{Results:}

The students' stories and poems described numerous very different situations where they had felt moved, by fear, by compassion, by injustice. The stories involved a collection of different sites from people's homes, to mental health facilities to acute wards and a wide range of other people from patients and service users to practice educators, visiting university tutors, nursing and medical staff. All of the writing displays the stressful and difficult attempts the students make to appear professional even when emotionally challenged and when they feel they have to manage their emotions.

I have selected just a few pieces of the work to illustrate some of the variety of situations in which they felt they had to manage their emotions. These are not representative of anything other than the situation they describe but they evoke the 
experience, the complexity and the 'feel' of the experience in a way that captures students' emotion management. The findings are a mixture of student writing and group discussions. The writing is in italics in a box to distinguish it from the discussion.

\section{Performing the professional:}

The second exercise in group two was to write about their professional face.

\section{Mirror Mirror}

Calm complexion from arriving early and having time to acclimatise

Hair clean and round my face. Eyes bright, no bags about.

The Golden thread is lifting my chin and relaxing my shoulders back and down.

Darcey's necklace is being shown off

Eyes and ears are keen but relaxed.

Few frowns or manic laughs, so high emotion lines are at rest.

A sense of consummate professional glints in the eye and curls up an extra corner of my smile.

Information systematically being projected Mission Impossible

style on my retina.

Diane 2.2.

This piece was met with laughter by the group and the following exchange:

Wow

I hope I

Diane: because I cycle everywhere I always arrive looking shocking (laughter from group) ...........and then the golden thread in various classes and martial arts they always taught you to envisage a golden thread, kind of lifting you

Yea

Diane: ...and your shoulders falling back down and your head up .and them am, you know Strictly Come Dancing - you know Darcey (yes, yea) she said envisage wearing a necklace, you know ,to just bring your shoulders back - so sounds like wearing Darcey's necklace then (laughter from group)

The performance aspects of the face and posture Diane saw when she thought of herself as a professional are related to film and television as well as martial arts and seemed to me to be very much about a 'show'. She uses words such as golden, 
necklace, glint and curl. The title she gave to the piece of writing relates directly to the tale of Snow White. Diane's picture of herself as a professional is the idealised, perfect one she strives to be which she contrasts with her untidy and disorganised 'self'. It also involves her hiding any 'high emotion lines' that correspond to Hochschild's (1983) concepts of surface acting.

Other responses to the prompt were slightly different and explicitly describe the effort of hiding emotion:

Hair tied back in a neat pony tail. Eyes alert. Wide open. Smile fixed, not quite real. Face open, but closed. Expression changeable- smile fixed. Smile goes, mouth opens and noises of sympathy and agreement come out. Forehead furrows and eyes squint in a look of forced concentration. Always interested and engaged.But closed. True emotion hiding behind eyes that show what the other person wants to see. Emotions there for only the most perceptive. Most see a motivated, interested, concentrating, never tired, always willing student.

Becky 2.2

This was met with an expression of group awe:

Group: wow ,Phoaw

Me : that captures the hard work you have to put in to

Becky - yea - to just appearing interested

(Group laughter)

Becky - it's like I am interested, but I have to appear interested

Huge group laughter

Becky's piece found some resonance with the rest of the group. Becky focuses on how she appears to other people on placement who may be watching her and on the effort required to meet the standards she presumes are asked of her. Part of these standards she assumes is to hide 'true' emotion and only present what they want to see. Twice she mentions how closed she is: 'Face open, but closed,' 'Always interested and engaged. But closed'. The need to appear interested, not just to be interested was met with loud laughter from the group which I assumed to be recognition and is part of these students' beliefs about appearing and embodying the professional which again relate to Hochschild's concepts of surface and deep acting .

Fear: 
Two of the participants had been on placements in secure settings and both wrote about times when they had felt afraid but had had to control that fear. This next extract came from Alice's writing which she did not read out to the group. It also demonstrates the link between managing emotions and wanting to pass the placement. Alice wrote this in the final group after the prompt to think about where the 'feeling rules' come from.

In one of my first supervisions my educator told me I had to be more outgoing and approach the patients in the leisure group, chat with them and be more active in the group. She said I would have to participate more if I wanted to do well on this placement. I was upset that I appeared to not be participating. I wanted to do really well and was a bit shocked I wasn't. I had to put on a brave face, smile at her and agree to everything she said. I brought this brave face to the next leisure group and pretended to not feel scared or intimidated by the patients. I still wasn't sure what to do or where to put myself in the room. I decided to pretend I was acting a part; I was confident, chatty, outgoing, and active. I greeted everyone with a smile, started conversations, invited myself to join in games, asked about how people were feeling, tried to find a common ground and chat about common interests. It seemed to be working, people were responding well to me. My educator was pleased and started to receive good reports about me. Soon the 'acting' became more natural and I eased into my role. I felt a little bit more comfortable but I still found it difficult to have to be constantly aware what the patients were capable of and this made me feel nervous and vulnerable.

Alice 4.3

In this piece Alice articulates the process she went through in learning how to act being a competent professional in a challenging area. She describes both how she learnt to hide her fear and the role of the Practice Educator in this 'disciplinary' process.

Her writing tells of a pragmatic decision she made to act the professional because as she states, she wants to pass the placement and in order to do that she has to behave in a way that is acceptable not just to her Practice Educator but also to other professionals in the team ('started to receive good reports about me'). This type of emotion management would be described as prescriptive by Bolton (2005) (as it specifically relates to the requirements of a professional occupational therapist in this area) and instrumental by Theodosius (2008) as she suppresses her own emotions in order to make the patient feel more confident in her and what is happening. 
Although she says she was able to do this acting, she did not find it any easier to deal with the realisation of the patients' criminal offences and her feelings about this were still there and difficult to manage. In this aspect of the placement, power seems to reside explicitly with the Practice Educator and the professional team who will give their judgement on her professional capabilities and be the gate keepers of the profession. Alice must mange her emotions to perform the professional and assume her professional power over the patients.

\section{Patients as learning objects}

Diane wrote a small piece as a poem in Group 4 in response to the exercise about where the feeling rules came from. She was on a placement on a ward where some people had severe respiratory disease and to me, as a university tutor involved in the whole process of educating health care professionals, this piece of writing was one of the most striking pieces from all the workshops.

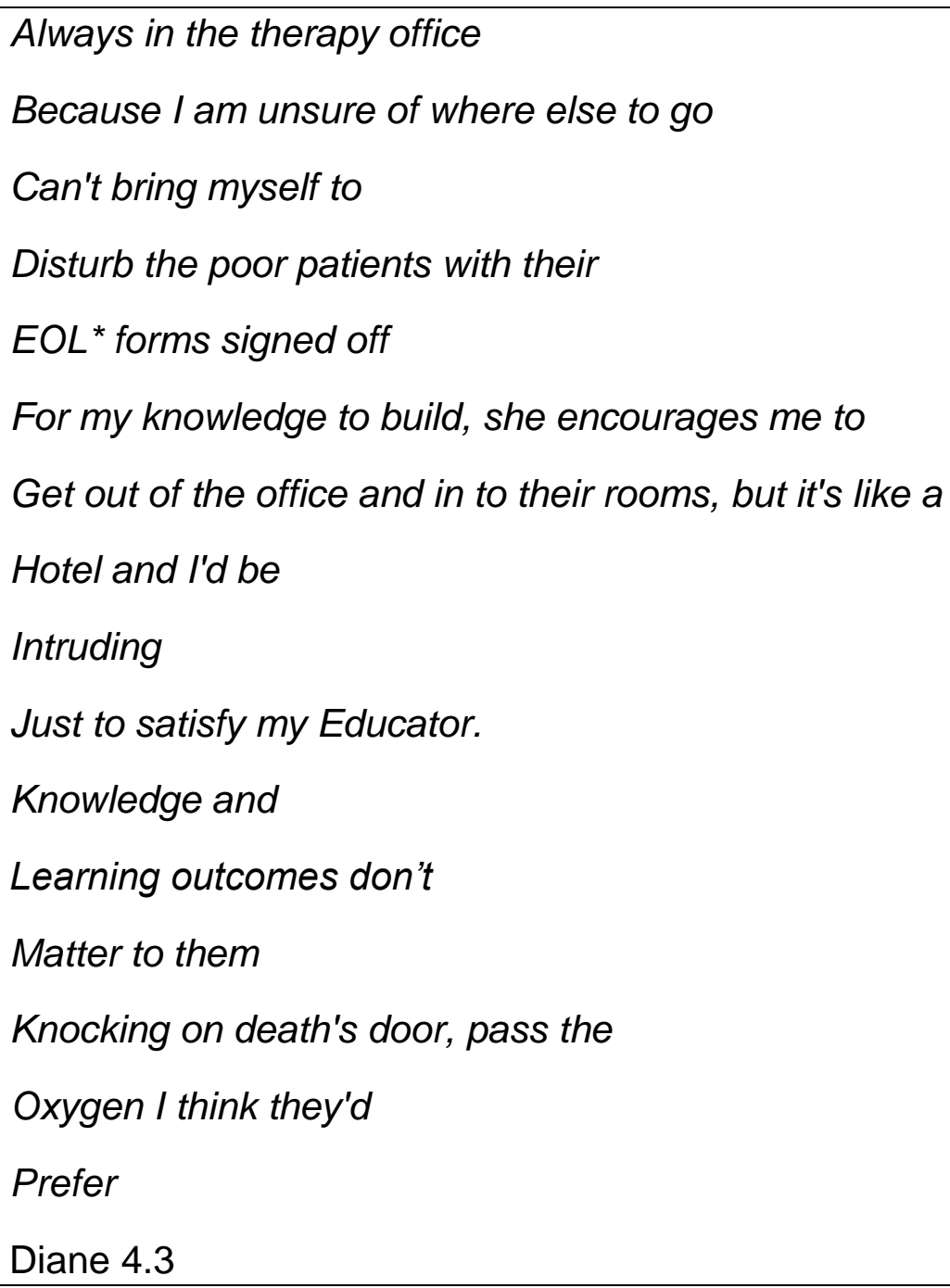


( ${ }^{\star} \mathrm{EOL}$ forms are End of Life forms)

There was an overwhelming sense of discomfort in this poem about using patients for learning. Diane discussed this in the group after reading out the poem:

Diane: I felt as if I was using up their last breath that they couldn't use on their children and I was just like - I don't want to go and talk to them, I'm struggling (she laughs) but she was really keen I think for me to better understand the condition - I was like, I think l'd rather read about it than get them to tell me (laughter from group)

Me: that's really powerful, that thing about using up their last breath and them not being able to speak -

that's horrible ( from group)

Diane: yea and on the placement I kind of realised just how disabling it was, because they wouldn't be able to participate in conversations or make their thoughts known, they were at the very, well, end stages, ...so yea, to take away their last , I mean it is a Chinese proverb, like you've only got so many breaths in them - so to be taking them away, just to satisfy my learning outcomes, I was like (laughs), I'm not comfortable with that.

\section{Mmmm}

silence

The silence at the end there felt like it was about trying to let the impact of what she had said settle. Instead of being out on the ward, talking to these patients so she could learn about their medical 'conditions', she preferred to hide in the office. Diane in this case tried to resist the demands on her that she talk to the patients so she could learn from them. In Discipline and Punish. The Birth of the Prison (1977), Foucault discusses how the examination is at the heart of disciplinary technology and it 'manifests the subjection of those who are perceived as objects and the objectification of those who are subjected' ( $p 184-185$ ). This describes exactly what was being asked of Diane, to go and talk to the patients to find out more about their respiratory conditions. Diane's emotional response to this however makes her question and resist. The accepted professional practice is to emotionally distance oneself from the patient (Smith and Kleinman 1989) and justify this by the need to learn from them in order to become a better professional and thereby benefit others 
in the future. Diane however resists the legitimacy of this justification and in doing resists performing as the professional in this instance.

This poem from Diane again illustrates how emotion management is part of making students and health professionals position the patients as 'other' and object in order to constitute themselves as different, as professionals with expert knowledge.

\section{Discussion and implications:}

The student writing vividly told me about how managing emotion was a powerful part of much of their learning and practice on placement. What my research showed is how this was felt by the students in this project and how this was a moveable and constantly negotiated process, not a fixed one dependent on the type of healthcare, the setting or the Practice Educator. The writing gave a sense of the struggles to become and perform the professional in the 'complex social contexts' (Cope et al, 2000 p852) that are placements. The emotion management in which the students engaged was a complex part of the multiple discourses around them as students and as potential professionals, being assessed. They had to manage their emotions on many levels, to appear competent to their Practice Educators as well as demonstrate their ability to manage their emotions in order to ultimately manage those of the patients.

The participants' writing illustrated how the students were subject to 'hierarchical observation' (Foucault, 1977) and assessment to enforce disciplinary norms of emotion management. This was mediated through the university assessment forms and the watchful eyes of their assessors in practice, the Practice Educators. This research however also showed how the students themselves operationalised the emotional rules through 'technologies of the self' (Foucault, 1988). Occupational therapy students are confronted with ambivalent and even contradictory theory and practice around holism, therapeutic use of self and client centred practice as they are required to perform their professional identities within this medical model health care system. The profession's adaptation to the managerialist, medically dominated health service in the UK (Clouston and Whitcombe, 2008) has challenged some of the central tenets of the profession's philosophy such as holism and client centred practice. This ambivalence has been a part of the profession for many years and was exposed over thirty years ago by Peloquin (1989). The ambivalence itself was 
often the site of some emotional turmoil for students. What was evident in the students' writing in my research was an understanding of the need to manage their emotions in order to conform to professional norms but also, at times, a resistance to this and a questioning which is both overt and implied.

Although the profession has begun to (re) acknowledge the role of emotions in our practice, we need to explore alternative concepts of emotion other than just those underpinning emotional intelligence and benefit from important work being done across paradigms and across disciplines. We need as a profession to appreciate the complex mediating role of emotions and the affective impact of the health care environments on students and occupational therapy staff. If we only take a selfdisciplinary approach we are not benefitting from the wealth of research and theory about emotions that exists in the wider field.

\section{Limitations:}

This was a small study over just four writing groups with seven student participants. With more time the student participants may have become more confident in their creative writing abilities and felt more confident using the techniques to write about their placement experiences.

My role as an occupational therapy tutor undoubtedly impacted on what the student participants felt able to share with me. The discourses of good student professional circulate everywhere within health and social care spaces. The narratives are partial and situated and contextually involved.

The roles of the patients and clients in these narratives only appear from the point of view of the students. Further research incorporating writing from patients, students and professionals would produce a more complex and intriguing sense of the role of emotion management throughout the health and social care environment.

\section{Conclusion}

This research has made a substantive contribution to the body of knowledge about emotional labour and management, specifically by adding a new dimension to our 
understanding of its role in occupational therapy practice and placement learning. I have presented an alternative to the humanist view of individual professionals managing their own emotions to suggest that emotion management is a tool which professionals use to manage the flow of affect within the space that is health and social care in order to conform to the discourse of being a professional. This management is a discursive/affective practice to maintain the divisions between the roles of professional/patient within these settings.

I have presented these practices as occurring in multiple ways and sites that do not fit easily into models or codes of emotion management although there are resonances with some of these concepts. My research has resisted the quest to codify types of emotional labour or reduce it to a set of behaviours or competencies. It presents an alternative view of emotion management to the one underpinning emotional intelligence. Rather than viewing emotion management as an individual technique or skill this research has sought to show what it can both feel like to perform and what its role is within the power relationships within health and social care. The encounters and situations the students wrote about and talked about are everyday occurrences on their placement but they are barely represented in the discourse of occupational therapy professional education.

\section{Key Findings:}

- Emotion management is an integral part of practice which has received little attention in education.

- Learning to act as a professional involves emotion management as a 'technology of the self'

What the study has added: The evocation of placement learning recalls the felt experience and affective dimension of learning. It brings a new perspective to the understanding of emotion management in health care practice. 


\section{$\underline{\text { References: }}$}

Andonian L (2013) Emotional intelligence, self-efficacy and occupational therapy students' fieldwork performance. Occupational therapy in health care. 27 (3) 201 215

Andrews M, Squire C, Tamboukou M (2013) (eds.) Doing narrative research. London: Sage

Barlow C, Hall BL (2007) What about feelings? A study of emotion and tension in social work field education. Social Work Education 26 (4) 399 - 413

Bochner AP Ellis C (2003) An introduction to the arts and narrative research. Qualitative Inquiry 9 (4) 506-514

Bolton S (2005) Emotion management in the workplace. Basingstoke: Palgrave Macmillan

Campos J, Walle EA, Dahl A, Main A (2011) Reconceptualizing emotion regulation. Emotion review. 3 (1) 26 - 35

Chaffey L, Unsworth C, Fossey E (2012) The relationship between intuition and emotional intelligence in occupational therapists in mental health practice. American Journal of occupational therapy. 66 (1) 88 - 96

Clouder L (2006) Caring as a 'threshold concept': transforming students in higher education into health (care) professionals. Teaching in higher education. 10 (4) 505 $-517$

Clouston, T J, Whitcombe, S (2008) The professionalization of occupational therapy: a continuing challenge. British Journal of Occupational Therapy. 71(8) 314 - 320

Cope P, Cuthbertson P, Stoddart B (2000) Situated learning in the practice placement. Journal of advanced nursing. 31 (4) 850 - 856

Denzin NK, Lincoln YS (2013) The landscape of qualitative research. 4th Ed. Thousand Oaks California: Sage 
Dwyer, S (2007) The emotional impact of social work practice. Journal of Social Work Practice. 21 (1) 49 - 60

Ellis C S, Bochner A (2000) Autoethnography, personal narrative, reflexivity: Researcher as subject. 733-768. In The Handbook of Qualitative Research. eds. Denzin N, Lincoln Y. London: Sage

Egan M (2007) Speaking of suffering and occupational therapy. Canadian journal of occupational therapy. 74 (4) 293 - 301

Foucault M (1977) Discipline and punish: the birth of the prison. Penguin: London Foucault M (1982) The subject and power. In Dreyfus NL, Rainbow P (1986) Michel Foucault. Beyond structuralism and hermeneutics. Brighton: Harvester press Foucault M (1988) The care of self: the history of sexuality. Vol 3.London: Viking Gergen KR (1999) An invitation to social construction. London: Sage Hochschild, A R $(1983,2003)$ The managed heart: commercialization of human feeling. London. University of California Press

Hooper B, Wood W (2002) Pragmatism and structuralism in occupational therapy: the long conversation. American journal of occupational therapy. 56 (1) 40 - 49

Ingram R (2015) Exploring emotions within formal and informal forums: messages from social work practitioners. British journal of social work. 45896 - 913

James N (1989) Emotional labour: Skill and work in the social regulation of feeling. Sociological review. 37 (1) 15 - 42

Lather P (1993) Fertile obsession: Validity after post structuralism. Sociological Quarterly. 34 ,(4) 673 - 693

MacLure M (2013) Classification or wonder? Coding as an analytic practice in qualitative research. In Coleman $\mathrm{R}$, Ringrose (Eds) Deleuze and research methodologies. Edinburgh: Edinburgh University Press.164 - 18 
Mann S (2005) A healthcare model of emotional labour. Journal of health organisation and management. 19 (45) 304 - 317

McClure R, Murphy C (2007) Contesting the dominance of emotional labour in professional nursing. Journal of health organisation and management. 21 (2) 101 120

McKenna J, Mellson J (2013) Emotional intelligence and the occupational therapist. British Journal of Occupational Therapy 76 (9) 427 - 430

McNaughton N (2013) Discourse(s) of emotion within medical education: the ever present absence. Medical education. 4771 - 79

Monrouxe LV, Rees CE, Endacott R, Ternane E (2014) Even now it makes me angry: healthcare students' professional dilemmas narratives. Medical education. 48 (5) 502 - 517

Nicholls $L$ (2007) A psychoanalytical discourse in occupational therapy. In Contemporary issues in occupational therapy: reasoning and reflection. Creek J, Lawson-Porter A (eds) Chichester: John Wiley and sons

Nicholls L (2013) Psychoanalytic thinking in occupational therapy: symbolic, relational and transformative. Oxford: Wiley-Blackwell

Peloquin S (1989) Sustaining the art of practice in occupational therapy. American journal of occupational therapy. 43 (4) 219 - 226

Richardson L (2000) Evaluating ethnography. Qualitative Inquiry. 6253 - 256

Riley R, Weiss MC (2016) A qualitative thematic review: emotional labour in healthcare settings. Journal of advanced nursing. 72 (1) $6-17$

Smith P (1992) The emotional labour of nursing. London: Macmillan

Smith AC, Kleinman S (1989) Managing emotions in the medical school: students' contacts with the living and the dead. Social Psychology Quarterly 52 (1) 56 - 69 
Tamboukou M (2003) Interrogating the emotional turn: making connections with Foucault and Deleuze. European journal of psychotherapy, counselling and health. 6 (3) 209 - 223

Theodosius C (2008) Emotional labour in health care. The unmanaged heart of nursing. Abingdon: Routledge

Zembylas M (2007) Theory and methodology in researching emotions in education. International journal of research and method in education. 30 (1) 57 - 72 